\title{
EVALUATION OF NOOTROPIC ACTIVITY OF ACHYRANTHES ASPERA LEAVES EXTRACT IN WISTAR RATS
}

\author{
DIVYA BHARGAVAN ${ }^{1 *}$, SUCHETHA KUMARI ${ }^{2}$, DEEPA B ${ }^{1}$ \\ ${ }^{1}$ Department of Pharmacology, K S Hegde Medical Academy, Mangalore, Karnataka, India. ${ }^{2}$ Department of Biochemistry, K S Hegde Medical \\ Academy, Mangalore, Karnataka, India. Email: divyabhargavan@rediffmail.com \\ Received: 07 July 2018, Revised and Accepted: 30 July 2018
}

\section{ABSTRACT}

Objective: The objective of the study was to evaluate the nootropic activity of hydroalcoholic extract of Achyranthes aspera leaves using elevated plus maze and radial arm maze.

Methods: Adult Wistar rats were allotted to three groups; Group 1 served as control, Groups 2 and 3 received $200 \mathrm{mg} / \mathrm{kg}$ and $400 \mathrm{mg} / \mathrm{kg}$ of AA extract, respectively, orally for 2 weeks after which the extent of improvement of memory was assessed.

Results: AA showed nootropic activity in both elevated plus maze and radial arm maze. $200 \mathrm{mg} / \mathrm{kg}$ of AA extract showed better improvement in learning and memory compared to $400 \mathrm{mg} / \mathrm{kg}$.

Conclusions: These results indicate that AA leaves extract clearly exhibited the improvement in learning and memory.

Keywords: Achyranthes aspera, Nootropic, Elevated plus maze, Radial arm maze.

(C) 2018 The Authors. Published by Innovare Academic Sciences Pvt Ltd. This is an open access article under the CC BY license (http://creativecommons. org/licenses/by/4. 0/) DOI: http://dx.doi.org/10.22159/ajpcr.2018.v11i12.28314

\section{INTRODUCTION}

Memory is the power of our mind to store and process facts, impressions, habits, and skills [1]. Memory makes us capable to build a relationship and to learn and adapt from previous experiences, whereas learning is a process by which we acquire knowledge and modify our behavior accordingly. Memory and learning are interconnected processes controlled by the coordinated activity of molecules, synapses, cells, and neural network within the brain [2].

Cognitive function is a process of thought information processing view of an individual's psychological functions. It involves attainment of information and thereby knowledge [3]. Cognitive abilities are brain-based skills we need to carry out any task from the simplest to the most complex. Cognitive function is negatively affected by aging, poor physical health, depression, low education, and socioeconomic status [4]. Brain functions involved in cognition are perception, attention, memory, motor skills, language, visual and spatial processing, and executive functions [5]

Thinking skills or intellectual abilities are used for perceptions, acquiring understanding, and responding to information presented to a patient. Cognitive dysfunction is the loss of these abilities. This can affect persons' thought, memories, and reasoning capabilities [6]. Most severe form of cognitive dysfunction is commonly shown in Alzheimer's, chronic fatigue syndrome, multiple sclerosis, schizophrenia, etc. Some of the cognitive dysfunctions are temporary and can improve over time as the disease or disorder begins to improve or can worsen without improvement at all $[7,8]$.

Achyranthes aspera (AA) is widely used as a nootropic agent in traditional medicine not many studies have been done in this regard [9]. AA belongs to Amaranthaceae family and is commonly known in English as rough chaff tree. AA is a herb with a woody base which grows to $2 \mathrm{~m}$ height. The leaves are thick, ovate, or rounded [10]. AA is commonly found at wasteland and as a roadside weed throughout India. Its roots, shoots, and leaves are commonly used in traditional medicine for various ailments [11]. Studies have reported that AA has antiparasitic, hypoglycemic, hepatoprotective, analgesic, anti-inflammatory, antimicrobial, nephroprotective, antidepressant, and antioxidant properties [12-15]. Phytochemical analysis of AA has reported the presence of alkaloids, flavonoids, tannins, saponins, oleanolic acid, and ecdysterone [16].

\section{METHODS}

Preparation of AA hydroethanolic extract

The leaves were collected and identified by a botanist. They were shade dried and coarsely powdered. This powder was extracted with $90 \%$ ethanol in a Soxhlet apparatus. The extract was evaporated using rotary evaporator and administered to the rats. The yield of the extract was $12 \%$.

\section{Animals}

Wistar albino rats of female sex weighing about 150-200 g were used for the study. The animals were procured from animal house, KSHEMA. They were housed in polypropylene cages and maintained under standard temperature conditions. They were given food pellets and water ad libitum. Animal ethics committee approval was taken before the study. This study was carried out with the approval of Institutional Animal Ethics Committee, KSHEMA. The animals were divided into three groups, Group 1 - control, Group 2 received $200 \mathrm{mg} / \mathrm{kg}$ of AA p.o, and Group 3 received $400 \mathrm{mg} / \mathrm{kg}$ of AA p.o. The experimental period was for 4 weeks.

\section{Experimental procedure}

All animals were evaluated for spatial memory by elevated plus maze and radial arm maze $1 \mathrm{~h}$ after the last dose.

Assessment of learning and memory using elevated plus maze The elevated plus maze consists of two open arms and two closed arms fixed to a central platform. The arms were opposite to each other, and the maze was elevated to a height of $50 \mathrm{~cm} .1 \mathrm{~h}$ after the last dose, each rat was placed at the end of the open arm facing away from the 
platform. Time taken by the animal to move from one end of the open arm into one of the closed arms with its four legs was recorded known as transfer latency. Retention of this memory was examined $24 \mathrm{~h}$ after the $1^{\text {st }}$ day. The reduction in transfer latency can be attributed to the improvement of memory [17].

\section{Assessment of learning and memory using radial arm maze}

The radial arm maze consists of equally spaced eight arms extending from a central platform and was positioned $50 \mathrm{~cm}$ above the floor. Partially baited radial arm method was followed in this study where food cups located at the end of four arms were baited with food reinforcements (Kellogg's moons and stars). The experiments were carried out in a well light room with distinct cues, which was constant throughout the experiment. The animals were kept on a restricted diet, and the body weight was maintained at $85 \%$ of free-feeding weight. The rats were given acclimatization sessions on the maze 2 days before the beginning of training where each rat was allowed to explore the maze for $10 \mathrm{~min}$ [18].

During the acquisition trial, the rats were given two trials per day until they achieved the learning criteria. The maze was cleaned with alcohol after each trial and was baited with food. The rats were released into the center of the maze and allowed free choice. When the rats reached the end of the baited arm or ate the bait, an arm choice was recorded and the time taken for the acquisition was noted. A reference memory error (RME) marks an entry into an unbaited arm and working memory error was a reentry into the arm. Training was continued till the animal attained the criteria of $80 \%$ correct choices. A retention trial was conducted 10 days after the learning trial and percentage correct choices, reference and working memory errors were recorded [19].

\section{Statistics}

Data were expressed as mean \pm standard deviation. One-way analysis of variance (ANOVA) was carried out and statistical comparisons among groups were performed by Tukey's test. $p<0.05$ was considered statistically significant

\section{RESULTS}

The AA-treated group reveals a significant increase in the percentage of the correct choices compared to the control groups $(\mathrm{p}<0.001$, whereas no significant difference was found between the two treated groups. Treated rats reached a criterion of $80 \%$ correct choices after 14 trials on the $7^{\text {th }}$ day of training, they reached a value of $87.37 \pm 11.24$ and $84.43 \pm 5.06 \%$ of correct choices, respectively (Table 1 and Fig. 1).

\section{The total time required for acquisition}

The total time required to complete the task was also significantly less in the treated group $(\mathrm{p}<0.001)$. By the final day of training, average latencies were $<10 \mathrm{~s}$. No rat made an arm entry error on the final day of acquisition. Performances improved over sessions, but the effect was considerably more for the treated group (Fig. 2).

The rats in treated group showed fewer RMEs and working memory errors compared to control from the $1^{\text {st }}$ to $9^{\text {th }}$ day. For AA-200 group showed no RME on day 8 and day 9 ( $\mathrm{p}<0.001$ ) (Figs. 3 and 4).

Table 1: Effect of Achyranthes aspera on the behavior of rats in elevated plus maze

\begin{tabular}{lll}
\hline Group & $\begin{array}{l}\text { Transfer latency on the } \\
\mathbf{1 4}^{\text {th }} \text { day }\end{array}$ & Transfer latency after $\mathbf{2 4} \mathbf{~ h}$ \\
\hline Control & $55 \pm 1.9$ & $25 \pm 1.1$ \\
AA200 & $46.25 \pm 2.18$ & $18.25 \pm 3.53 \mathrm{a}$ \\
AA400 & $54.5 \pm 5.96$ & $21.25 \pm 3.48$ \\
\hline
\end{tabular}

Data expressed as mean $\pm \mathrm{SD}$, ${ }^{\mathrm{a}} \mathrm{p}<0.001$ when compared to control rats.

n=6, AA 200: Achyranthes aspera $200 \mathrm{mg} / \mathrm{kg}$, AA 400: Achyranthes aspera

$400 \mathrm{mg} / \mathrm{kg}$. SD: Standard deviation

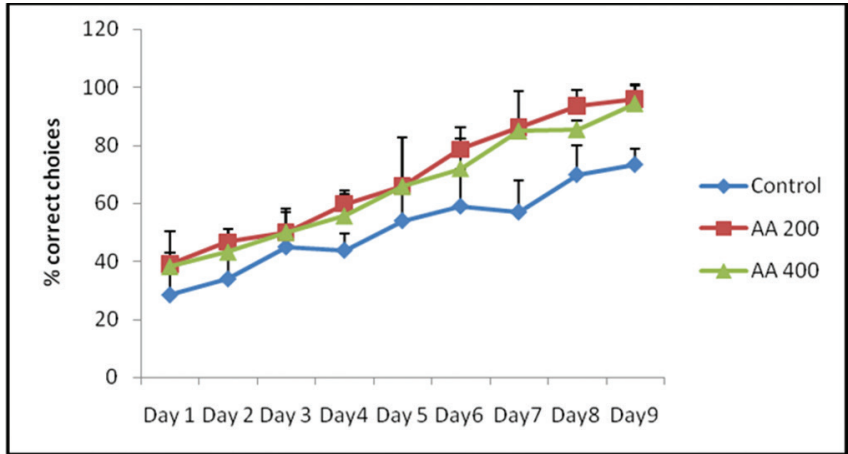

Fig. 1: Percentage of correct choices in partially baited radial arm maze. Data expressed as mean \pm standard deviation, $n=6$

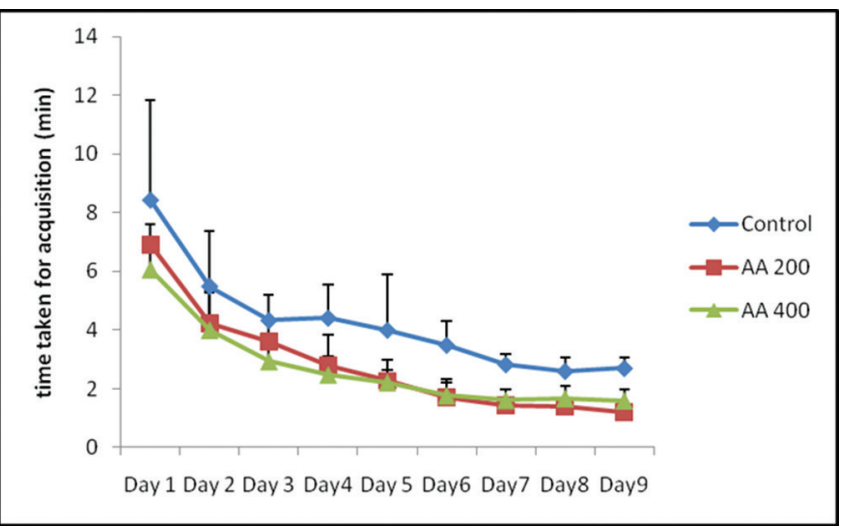

Fig. 2: Time taken for acquisition in partially baited radial arm maze. Data expressed as mean \pm standard deviation. $n=6$

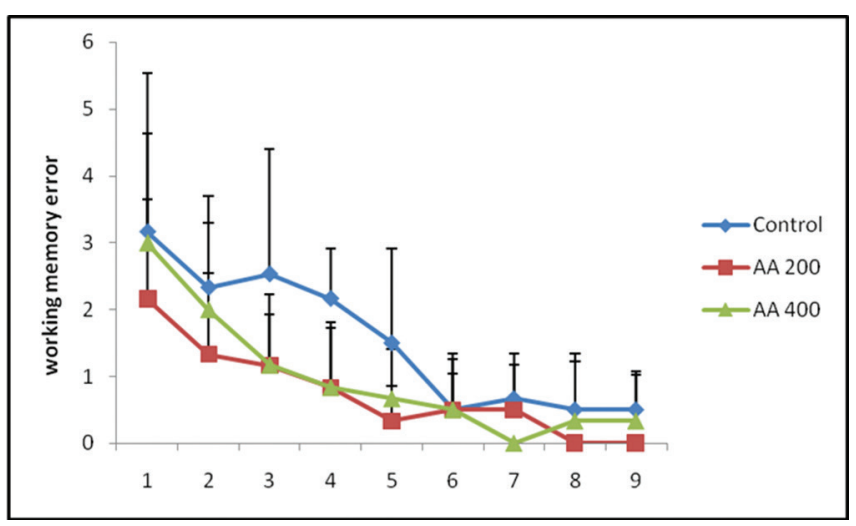

Fig. 3: Working memory errors in partially baited radial arm maze. Data expressed as mean \pm standard deviation, $n=6$

\section{Retention memory}

A one-way ANOVA found no significant difference between the control and treated groups.

\section{DISCUSSION}

In this study, nootropic activity of AA was evaluated by elevated plus maze and radial arm maze. Both elevated plus maze and radial arm maze clearly demonstrated the improvement in learning and memory.

Elevated plus maze serves as an exteroceptive model to evaluate learning and memory. Transfer latency is defined as the time taken by the rat to move from open arm to closed arm. Reduced transfer latency indicates memory improvement [20]. AA extract given for 4 weeks showed improvement in memory compared to control groups. 


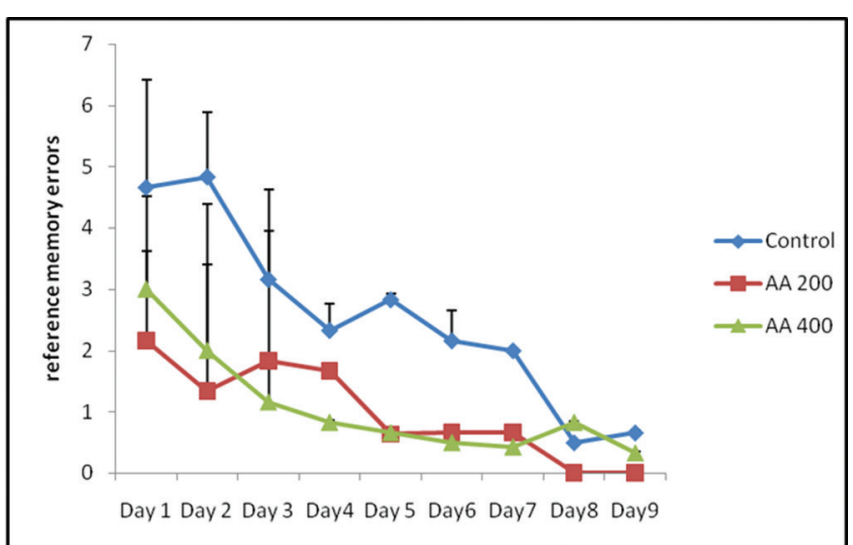

Fig. 4: Reference memory error in partially baited radial arm maze. Data expressed as mean \pm standard deviation. $n=6$

The radial arm maze is a standard and well-validated test of spatial learning and memory. The previous studies of radial arm maze behavior in rodents reports, working errors are regarded as "short-term" memory deficits and reference errors have been regarded as evidence of "long-term" memory deficits [21].

In this study, fewer sessions were required to reach criterion performance for the treated rats than the control group. The rats in the treated group showed more progress in the selection of correct choices compared to the control group from the $1^{\text {st }}$ to $9^{\text {th }}$ day. The rats treated with AA $200 \mathrm{mg} / \mathrm{kg}$ showed better learning curve, made more correct choices, fewer RME, and lesser time is taken for acquisition compared to AA $400 \mathrm{mg} / \mathrm{kg}$ in radial arm maze and decrease in transfer latency in elevated plus maze.

In silico guided nootropic prediction of AA plant has been reported in an earlier study and confirmed in vivo using radial arm maze, passive shock avoidance, and novel object recognition tests in mice [22].

The protective effects of AA extract can be explained by its antioxidant and apoptotic effects reported in the previous studies [23].

To summarize, we demonstrated that AA extract significantly improves the working memory assessed by eight-arm radial maze and elevated plus maze. The findings from this study indicate that AA has protective effect on hippocampus-dependent spatial learning and memory. However, further studies are required to know the molecular basis of beneficiary actions of AA.

\section{ACKNOWLEDGMENT}

Authors are thankful to late Dr. Arunachalam Kumar for his guidance during the study and Nitte (Deemed to be University) for supporting and funding this project.

\section{AUTHORS' CONTRIBUTION}

All authors have made substantial contribution to the work reported in the manuscript.

\section{CONFLICTS OF INTEREST}

The authors declare that they have no conflicts of interest.

\section{REFERENCES}

1. Solomon AM, Henri C, Sushmitha, Charles, Paartha, Melwin, et al. Neuron the memory unit of the brain. IOSR J Comput Eng 2015;17 Suppl 4:48-61.

2. Kandel ER. The molecular biology of memory storage: A dialogue between genes and synapses. Science 2001;294:1030-8.

3. Eysenck MW, Derakshan N, Santos R, Calvo MG. Anxiety and cognitive performance: Attentional control theory. Emotion 2007;7:336-53.

4. Gallo LC, Matthews KA. Understanding the association between socioeconomic status and physical health: Do negative emotions play a role? Psychol Bull 2003;129:10-51.

5. Schmahmann JD. Disorders of the cerebellum: Ataxia, dysmetria of thought, and the cerebellar cognitive affective syndrome. J Neuropsychiatry Clin Neurosci 2004;16:367-78.

6. Buckner RL, Carroll DC. Self-projection and the brain. Trends Cogn Sci 2007; 11:49-57.

7. Wulff K, Gatti S, Wettstein JG, Foster RG. Sleep and circadian rhythm disruption in psychiatric and neurodegenerative disease. Nat Rev Neurosci 2010;11:589-99.

8. Albert MS, DeKosky ST, Dickson D, Dubois B, Feldman HH, Fox NC, et al. The diagnosis of mild cognitive impairment due to Alzheimer's disease: Recommendations from the national institute on agingAlzheimer's association workgroups on diagnostic guidelines for Alzheimer's disease. Alzheimers Dement 2011;7:270-9.

9. Girach RD, Khan AS. Ethnomedicinal uses of Achyranthes aspera leaves in Orissa (India). Int J Pharmacogn 1992;30 Suppl 2:113-5.

10. Kamalakkann K, Balakrishnan V. Studies on the effect of antidiabetic activity of Achyranthes aspera L. on alloxan induced wistar rats. Int J Pharm Pharm Sci 2015;7 Suppl 9:61-4.

11. Goyal BR, Goyal RK, Mehta AA. Phyto-pharmacology of Achyranthes aspera: A Review. Pharmacogn Rev 2007;1 Suppl 1:143-50.

12. Kothavade PS, Bulani VD, Juvekar AR. Attenuating effect of triterpenoid saponin rich fraction of Achyranthes aspera Linn. on acute and chronic inflammation in experimental rats. Int J Pharm Pharm Sci 2015;7 Suppl 7:134-8.

13. Akhtar MS, Iqbal J. Evaluation of the hypoglycaemic effect of Achyranthes aspera. J Ethnopharmacol 1991;31:49-57.

14. Dwivedi S, Dubey R, Mehtaz K. Achyranthes aspera Linn. (Chirchira): A magic herb in folk medicine. Ethnobot Lealf 2008;12:670-6.

15. Jayakumar T, Sridhar MP, Raghavaiah T, Ilayaraja M, Govindasamy S. Experimental studies of Achyranthes aspera (L) preventing nephrotoxicity induced by lead in albino rats. J Health Sci 2009;55:701-8.

16. Priya K, Krishnakumari S. Phytochemical analysis of Achyranthes aspera and its activity on sesame oil induced lipid peroxidation. Anc Sci Life 2007;27:6-10.

17. Itoh J, Nabeshima T, Kameyama T. Utility of an elevated plusmaze for the evaluation of memory in mice: Effects of nootropics, scopolamine and electroconvulsive shock. Psychopharmacology (Berl) 1990;101:27-33.

18. Bhagya V, Srikumar BN, Raju TR, Shankaranarayana Rao BS. Neonatal clomipramine induced endogenous depression in rats is associated with learning impairment in adulthood. Behav Brain Res 2008;187:190-4.

19. Karkada G, Shenoy KB, Halahalli H, Karanth KS. Nardostachys jatamansi extract prevents chronic restraint stress-induced learning and memory deficits in a radial arm maze task. J Nat Sci Biol Med 2012;3:125-32.

20. Olten DS, Collison C, Werz MA. Spatial memory and radial maze performance of rats. Learn Motiv 1997;10:117-40.

21. Culley DJ, Baxter MG, Yukhananov R, Crosby G. Long-term impairment of acquisition of a spatial memory task following isofluranenitrous oxide anesthesia in rats. Anesthesiology 2004;100:309-14.

22. Dinesh Y, Gawande R, Kumar G. Pharmacological validation of in-silico guided novel nootropic potential of Achyranthes aspera L. J Ethnopharmacol 2015;175:324-34.

23. Edwin S, Jarald E, Edwin DL, Jain A, Kinger H, Dutt KR, et al. Wound Healing and antioxidant activity of Achyranthes aspera Linn. Pharm Biol 2008;46 Suppl 12:824-8. 